\title{
Investigating participation in Advanced level mathematics: a study of student drop out
}

\author{
Andrew Noyes and Paula Sealey \\ University of Nottingham
}

\begin{abstract}
There has for some years been a growing concern about participation in university-entrance level mathematics in England and across the developed world. Extensive statistical analyses present the decline but offer little to help us understand the causes. In this paper we explore a concern which cannot be explored through national datasets, namely the retention of mathematics students on Advanced level mathematics courses. Drawing on survey data from fifteen secondary schools in the Midlands of England, we examine subject differences in decisions to study, withdraw from, and continue in a range of A level subjects. Not only is the rate of attrition from mathematics higher than most other subjects, but there are substantial differences between schools. In order to explore this high rate of attrition further we consider one school - Queensbury Park - in which a large proportion of students decided not to continue with their study of mathematics from year 12 to 13. Drawing on performance data and focus group interviews we explore some of the reasons for the students' decisions.
\end{abstract}

Keywords: Mathematics education, A level, participation, mixed methods

\section{Background}

Concerns about participation in Advanced level (or simply A level) school mathematics have been growing in recent years following a gradual decline in take up from the late 1980s (Matthews \& Pepper, 2007; Smith, 2004 , p. 2). Despite a recent upturn there is a long way to go to reach the current target of 70,000 completing A level mathematics by 2014. These concerns are part of a broader set of issues in developed countries about the adequate supply of science, technology, engineering and mathematics (STEM) workers (Committee on Science, Engineering and Public Policy, 2007; Gago, 2004; Roberts, 2002; Rocard, 2007). There is widespread agreement that advanced economies need to position themselves as leaders and innovators in the production and application of scientific and technological knowledge in order to secure their future economic prosperity. Across these and other reports it is clear that there is an ongoing problem of low, and in many areas decreasing, participation in STEM subjects and that policies aimed at tackling this have had little effect.

Here we limit our attention to the study of post compulsory mathematics in England, in particular universityentrance (Advanced) level. In England, young people complete their compuslory schooling at age 16 (Year 11) with the General Certificate of Secondary Education (GCSE) qualifications. Obtaining five or more higher grades $\left(\mathrm{A}^{*}-\mathrm{C}\right)$ allows students access to a wide range of further educational opportunities. The majority of those achieving this level at GCSE proceed to the traditional academic track of Advanced level awards (General Certificate of Education or GCE). These are the standard university-entrance qualifications and most students would study three or four subjects over the following two years, up to the age of 18 (Year 13). Sometimes a student might complete only half of one of these two-year, modular A level courses and receive an Advanced Supplementary (AS) award. Advanced level Mathematics is a pre-requisite for most Science, Technology, Engineering and Mathematics (STEM) courses in higher education and has been shown to increase future earning potential (Wolf, 2002).

A few studies have explored the reasons why students decide not to study mathematics at A level. Most recently Brown et al (2008) reported that "perceived difficulty and lack of confidence are important reasons for students not continuing with mathematics, and that perceived dislike and boredom and lack of relevance are also factors" (p. 3). They concluded that enjoyment was perhaps the most critical factor differentiating schools with high and low participation rates although it is not clear what the necessary conditions are for fostering such enjoyment. Mendick $(2005,2008)$ uses student case studies to explore the ongoing gender disparity in participation rates and Matthews and Pepper's (2007) report for the Qualifications and Curriculum Authority looks in depth at a range of statistical patterns of participation over the years. Elsewhere Hernandez-Martinez et al (2008) develop 'interpretive repertoires' of choice as a means of explaining students' reasons for choosing mathematical study at Advanced level. 


\section{The GMAP Project}

In this paper we want to explore a particular issue which has not been explored by these and other scholars, namely that of retention on A level mathematics courses. Given that national databases do not record whether students started courses but only that they completed them, we have little sense of what the broad picture of attrition is from A level subjects, in particular mathematics. It would also be helpful to know what factors influence students' decisions to withdraw ('drop out') from A level mathematics and, if there is significant between-school variation in attrition rates, In order to consider these issues we draw on part of a large and complex dataset from the Geographies of Mathematical Attainment and Participation (GMAP) Project. The GMAP project is a longitudinal, multi-layered, mixed-methods study exploring regional patterns of mathematics attainment and participation and the roles of families, peers, teachers and schools in creating these patterns. With a particular concern for social justice the project explores who gets to do what mathematics and where. The four layers of the study are:

1. Statistical analyses (descriptive, multilevel modelling) of attainment and social data from the National Pupil Database, focused on 16 and 18 year olds in the Midlands of England from 20042008

2. Mapping of the results from Layer 1 using Geographic Information Systems technology to explore the role of place in attainment and participation.

3. Questionnaire surveys of students in Year 7,11 and 12 and teachers in a sample of sixteen secondary schools (11-18) in one part of the Midlands

4. School case studies tracking Year 11 and 12 cohorts in half of the schools from Layer 3 to include teacher interviews, focus groups and some lesson observation.

One of the aims of the project is to reconsider what we mean by school effectiveness, and this might include the extent to which students persevere, enjoy and are successful in A level mathematics. The multilevel modelling in the project highlights considerable between-school variation in participation, or rather A level Mathematics completion (Author, 2009). For this reason we use the school as a unit of analysis herein and focus on one of the eight schools (Queensbury Park) which has a relatively high level of attrition from A level mathematics, both during Year 12 and at the transition into Year 13. Although this is an anonymised case and shares similarities with other schools/students we caution against hasty generalisation, but we are confident that some aspects of the findings have wider applicability.

In keeping with the mixed-methodology of the GMAP project we draw on quantitative and qualitative data to explore the issue of participation, or more particularly attrition, as evidenced at Queensbury Park. Here we use the Year 12 questionnaire data (completed spring 2008) from 15 schools, two of which share a Sixth Form Centre (for A level teaching). Around two thirds of the Year 12 students in these schools responded (although the response rate was variable) numbering 1181 in total. The surveys were administered through tutorial groups so we expect this to be a broadly representative sample. The survey explored students' decisions to study various A level subjects and the extent to which a range of factors was influential in the choice process. For students of mathematics, an additional set of questions explored their attitudes to the subject and a range of teaching and learning matters. Given that the surveys were completed between February and April there will be some variation in responses. However, our data from interviews with heads of department suggests that 'drop-out' from Year 12 had already taken place by February. Regarding aspirations to continue study to the second year of the programme, the survey data is less reliable and there were some small differences between those who planned to, and those who actually did, continue to the second year of A level study. For Queensbury Park we also have teacher records of successful transitions from Years 12 to 13.

In order to be able to match various strands of our data we asked students to put their names onto their surveys. Hence we can identify individual responses and link to attainment data from year 12 and to the focus group data we have. Focus group discussions were carried out with a teacher-selected sample of the year 12 students who had decided not to continue with their mathematical studies. We were not able to get access to all withdrawing students and indeed their participation was voluntary. Recordings of these 
interviews were transcribed and coded in Nvivo. A timeline for students' decision-making processes and the data collection is shown in Table 1.

\begin{tabular}{|l|l|l|}
\hline Year & Time & Activity \\
\hline \multirow{3}{*}{ Year 11 } & April 07 & Students submit their proposed AS subject choices \\
\cline { 2 - 3 } & August 07 & GCSE results published; students amend their AS subject selection \\
\hline \multirow{3}{*}{ Year 12 } & October 07 & $\begin{array}{l}\text { QP allows students to 'swap' AS subjects up to October half term if } \\
\text { not happy with choices. }\end{array}$ \\
\cline { 2 - 3 } & January 08 & $\begin{array}{l}\text { Students sit first AS module; some decide that AS mathematics is not } \\
\text { for them and withdraw. }\end{array}$ \\
\cline { 2 - 3 } & April 08 & $\begin{array}{l}\text { Module results published and may impact on future plans. Decisions } \\
\text { on module resits are made and intentions for A2 study clarified. }\end{array}$ \\
\cline { 2 - 3 } & July 08 & $\begin{array}{l}\text { Questionnaire with all Year 12 students } \\
\text { they do not wish to progress to A2. Focus groups discussions. }\end{array}$ \\
\cline { 2 - 3 } & August 08 & $\begin{array}{l}\text { AS results published - students may change their decision to } \\
\text { continue/drop mathematics based on their final AS grades }\end{array}$ \\
\hline Year 13 & September 08 & $\begin{array}{l}\text { Interview with Head of Department. School transition and } \\
\text { attainment data collected. }\end{array}$ \\
\hline
\end{tabular}

Table 1: Timeline for student action and data collection (boldface)

\section{Participation in A levels}

In Table 2 the results for all A level subjects with 100 or more starting students (in the dataset) are listed, in order of decreasing rates of non-completion of Year 12.

\begin{tabular}{lcccc}
\hline & $\mathrm{N}$ & $\begin{array}{l}\text { AS level } \\
\text { starters }\end{array}$ & $\begin{array}{c}\text { Y12 starters not } \\
\text { completing AS (\%) }\end{array}$ & $\begin{array}{c}\text { Y12 planning not to } \\
\text { continue to Y13 (\%) }\end{array}$ \\
\hline ICT/Computer Studies & 1064 & 192 & 14.6 & 12.2 \\
Mathematics & 1088 & 514 & 10.3 & 19.1 \\
Sociology & 1077 & 157 & 10.2 & 18.4 \\
English Language & 1086 & 204 & 9.8 & 12.5 \\
Art & 1061 & 129 & 8.5 & 8.5 \\
Physics & 1067 & 227 & 8.4 & 18.3 \\
Business Studies & 1075 & 205 & 8.3 & 14.4 \\
English Literature & 1125 & 371 & 7.5 & 19.2 \\
Psychology & 1093 & 318 & 7.2 & 20.0 \\
Biology & 1079 & 355 & 6.8 & 15.4 \\
Geography & 1069 & 209 & 5.3 & 20.2 \\
Chemistry & 1075 & 277 & 5.1 & 16.0 \\
History & 1089 & 299 & 5.0 & 21.5 \\
Religious Studies & 1068 & 124 & 4.8 & 23.7 \\
Sports Studies & 1055 & 158 & 4.4 & 16.6 \\
French & 1059 & 101 & 4.0 & 30.9 \\
\hline
\end{tabular}


Table 2: Withdrawal and planned continuation rates for a range of A level subjects from surveys across all participating schools

We can see that attrition from Year 12 (AS) mathematics is high, only being exceeded by ICT. English Literature is lower as are the sciences: physics, chemistry and biology. Mathematics is not so badly placed when considering the expected level of continuation from Year 12 to 13. Some subjects (e.g. French, 31\%) might well be suffering from school entry policies to Year 12 and the process of students reducing from 4 AS qualifications (in Year 12) to complete 3 A2 awards (in Year 13). The contrast with Art is striking but it is beyond the scope of this paper to explore these differences. Suffice to say that around $20 \%$ of AS mathematics students (a similar proportion to English Literature) were not expecting to continue to A2.

It is well documented that participation in A level mathematics is skewed towards those with higher GCSE grades - the 'clever core' (Matthews \& Pepper, 2007)(Author, forthcoming). We wondered how prior attainment (as evidenced in GCSE grade) related to the likelihood of withdrawal from Y12 and/or continuation to Y13. Table 3 shows the full extent of this question which tries to place students on a scale of engagement with A level mathematics from "I didn't consider studying this at A level" to "I am studying it and plan to continue in Y13". Admittedly we do not know at what point the decision was made in relation to the award of the GCSE but given that students' predicted grades would have informed decision-making processes we can assume that there is some validity in this data. The percentages here are of each grade, totalling to 100 across each row, for example $13.6 \%$ of students surveyed who had previously achieved a GCSE grade A in mathematics will complete AS but will not continue to A2.

\begin{tabular}{llllll}
$\begin{array}{l}\text { GCSE } \\
\text { maths } \\
\text { grade }\end{array}$ & $\begin{array}{l}\text { I didn't consider } \\
\text { studying this at } \\
\text { A level }\end{array}$ & $\begin{array}{l}\text { I considered } \\
\text { studying but } \\
\text { decided not } \\
\text { to start }\end{array}$ & $\begin{array}{l}\text { I started but } \\
\text { dropped it }\end{array}$ & $\begin{array}{l}\text { I am studying } \\
\text { now but don't } \\
\text { plan to continue } \\
\text { into Y13 }\end{array}$ & $\begin{array}{l}\text { I am studying it } \\
\text { and plan to } \\
\text { continue in Y13 }\end{array}$ \\
\hline A* & 4.2 & 4.2 & 2.1 & 6.3 & 83.2 \\
A & 17.8 & 13.3 & 7.1 & 13.6 & 48.2 \\
B & 49.8 & 17.4 & 5.9 & 8.4 & 18.5 \\
C & 78.6 & 12.9 & 3.8 & 1.4 & 3.3 \\
\hline
\end{tabular}

Table 3: Engagement with Advanced mathematics by prior GCSE attainment (percentages, $\mathrm{N}=1088$ )

We also wanted to consider whether these patterns of participation (and attrition) vary between institutions. In Table 4 the figures for mathematics in the fifteen responding schools (N.B schools C and D are combined into one centre) are recorded. They are included as raw data since the numbers are now quite small and so percentages could be misleading. Nevertheless the variations are considerable. School D only has 2 from 85 not completing AS which is particularly low. Comparing the number not planning to continue from the large cohorts in schools $\mathrm{E}$ and $\mathrm{H}$ also signals critical differences. However, we are not here conducting a cross-case analysis but rather focusing on one school.

There is considerable variation between these schools and although the percentages are easily skewed by a small number of students we can confidently say that there is some considerable difference between them, in terms of percentage starting, Year 12 attrition and continuation to A2. For school Q (Queensbury Park) the estimate that $36 \%$ of the AS mathematics cohort would not continue to Year 13 mathematics turned out to be reasonably accurate. In fact 13 students did not proceed to A2. Before considering Queensbury Park we ask what might be generating the above differences.

From interviews with the heads of mathematics it is clear that schools have different approaches to selection and support of mathematics students. The schools also have different entry policies to A level study and views on whether students should follow 3, 4 or more courses in Year 12. Moreover, it would be unreasonable to assume that the GCSE grade profile of each of these cohorts is the same, which would (see Table 3) have an impact on the figures in Table 4. So, although these figures do not in some ways compare like with like, there is probably enough variation to assume that the school (policy, advice, teaching, peer group) is having some impact upon participation rates. Indeed the multilevel modelling conducted in Layer 1 of the GMAP project (Author, 2009) suggests that after accounting for a wide range of individual and 
school variables (e.g. prior attainment, gender, ethnicity, socio-economic status, cohort mix and attainment) schools can be shown to account for around $20 \%$ of the unexplained variation in whether a student will complete any A level mathematics. With that in mind, looking in more detail at how this works out in a particular context (and range of contexts) is necessary.

\begin{tabular}{|c|c|c|c|c|c|c|c|c|}
\hline \multirow[b]{2}{*}{ School } & \multicolumn{5}{|c|}{ Number } & \multicolumn{3}{|c|}{ Percentage } \\
\hline & $\begin{array}{l}\text { Y12 } \\
\text { cohort } \\
\text { size }\end{array}$ & $\begin{array}{l}\text { starting } \\
\text { AS level } \\
\text { Maths }\end{array}$ & $\begin{array}{l}\text { dropped } \\
\text { maths } \\
\text { during } \\
\text { Y12 }\end{array}$ & $\begin{array}{l}\text { Plan to } \\
\text { withdraw } \\
\text { after AS } \\
\text { maths }\end{array}$ & $\begin{array}{l}\text { Plan to } \\
\text { proceed } \\
\text { to A2 } \\
\text { maths }\end{array}$ & $\begin{array}{l}\text { Of Y12 } \\
\text { cohort } \\
\text { starting AS } \\
\text { maths }\end{array}$ & $\begin{array}{l}\text { Of maths } \\
\text { starters } \\
\text { dropping out } \\
\text { during Y12 }\end{array}$ & $\begin{array}{l}\text { Of Y12 maths } \\
\text { completers } \\
\text { planning not to } \\
\text { continue to A2 }\end{array}$ \\
\hline $\mathrm{A}$ & 40 & 25 & 2 & 2 & 21 & 63 & 8 & 9 \\
\hline B & 79 & 37 & 3 & 6 & 28 & 47 & 8 & 18 \\
\hline $\mathrm{D}$ & 147 & 85 & 2 & 11 & 72 & 58 & 2 & 13 \\
\hline $\mathrm{E}$ & 96 & 45 & 7 & 2 & 36 & 47 & 16 & 5 \\
\hline $\mathrm{F}$ & 75 & 21 & 3 & 3 & 15 & 28 & 14 & 17 \\
\hline G & 97 & 52 & 6 & 13 & 33 & 54 & 12 & 28 \\
\hline $\mathrm{H}$ & 112 & 69 & 7 & 15 & 47 & 62 & 10 & 24 \\
\hline $\mathrm{J}$ & 84 & 28 & 5 & 3 & 20 & 33 & 18 & 13 \\
\hline $\mathrm{K}$ & 37 & 20 & 2 & 5 & 13 & 54 & 10 & 28 \\
\hline $\mathrm{L}$ & 55 & 24 & 0 & 5 & 19 & 44 & 0 & 21 \\
\hline M & 49 & 20 & 4 & 6 & 10 & 41 & 20 & 38 \\
\hline $\mathrm{N}$ & 89 & 38 & 3 & 7 & 28 & 43 & 8 & 20 \\
\hline $\mathrm{Q}$ & 67 & 32 & 4 & 10 & 18 & 48 & 13 & 36 \\
\hline $\mathrm{R}$ & 61 & 24 & 5 & 3 & 16 & 39 & 21 & 16 \\
\hline Total & 1088 & 520 & 53 & 91 & 376 & 48 & 10 & 19 \\
\hline
\end{tabular}

Table 4: Levels of engagement with Advanced level mathematics across a range of 11-18 schools. (Q - Queensbury Park)

\section{The Queensbury Park Mathematics Cohort}

Queensbury Park is a successful, suburban comprehensive school on the outskirts of a large city in the Midlands of England. The A level mathematics students are organised into two groups and complete three modules (Core 1, Core 2 and Mechanics 1) during Year 12. The groups are of mixed gender and prior attainment. In Table 5 the results for the 33 students that completed the AS course at QP are presented along with their final decisions on whether or not to continue the study of mathematics to A2.

Similar numbers of boys and girls complete the Year 12 course but generally the higher attainment of the boys might suggest that they are more likely to continue. However, the difference here might be more to do with prior attainment. Using the GCSE average points score $\left(A^{*}=8, A=7\right.$, etc) and the total AS score for mathematics (maximum 300), Chart 1 shows, for male and female students, who did not continue with their mathematics into Year 13. As we would expect, most of the students in the lower left portion of the charts, i.e. those with low prior attainment and low AS attainment are not continuing. What is more unexpected are those in the upper right quadrant, 3 girls and 1 boy.

We have survey responses for 26 of these 33 students. The surveys were completed in the spring of 2008 after the first module results were received. Of the ten students who planned to not continue to A2, eight of them did stop whilst two changed their minds and continued into Year 13. All ten were combining mathematics with arts, languages and humanities subjects. This is a clear distinction from the rest of the 
students (with one exception) who planned to continue to Year 13 and were also studying at least one science subject. However, half of this group who had intended to continue actually withdrew following their AS examination. All of these withdrawers attained $U$ or $E$ grades and so were either discouraged from continuing or decided to withdraw. Across the mathematics cohort students achieved about half a grade lower at AS than predicted by the ALIS ${ }^{1}$ system. Four of the five students who attained a higher grade than predicted were also studying physics AS. More generally, physics students actual grades were, on average, very close to the predicted ALIS grades whereas non-physics students were nearly one grade lower than expected on average. If commonly used prediction models (such as ALIS) cannot account for any variation in attainment that might be due, in part, to subject mixing, it seems likely that across a large population students combining mathematics with arts/humanities are more likely to feel that they have underachieved and so withdraw after Year 12.

The four high attaining withdrawers (represented by the four triangles in the top right part of Chart 1) were not doing mathematics anywhere else in their GCE courses due to their subject combinations but were all studying history ${ }^{2}$. Having introduced the 2007/8 year 12 cohort we now turn to the focus group data collected in the school.

\begin{tabular}{|l|l|l|l|l|}
\cline { 2 - 5 } \multicolumn{1}{c|}{} & AS Grade & $\begin{array}{l}\text { Continue } \\
\text { to A2 }\end{array}$ & $\begin{array}{l}\text { Stop after } \\
\text { AS }\end{array}$ & Total \\
\hline \multirow{5}{*}{ Girls } & A & 1 & 1 & 2 \\
\cline { 2 - 5 } & B & 1 & 1 & 2 \\
\cline { 2 - 5 } & C & 2 & 1 & 3 \\
\cline { 2 - 5 } & D & 2 & 1 & 3 \\
\cline { 2 - 5 } & E & 2 & 1 & 3 \\
\cline { 2 - 5 } & U & 0 & 4 & 4 \\
\cline { 2 - 5 } & Total & 8 & 9 & 17 \\
\hline \multirow{5}{*}{ Boys } & A & 4 & 0 & 4 \\
\cline { 2 - 5 } & B & 3 & 0 & 3 \\
\cline { 2 - 5 } & C & 0 & 1 & 1 \\
\cline { 2 - 5 } & D & 2 & 1 & 3 \\
\cline { 2 - 5 } & E & 2 & 2 & 4 \\
\cline { 2 - 5 } & U & 0 & 1 & 16 \\
\cline { 2 - 5 } & Total & 11 & 5 & 16 \\
\hline
\end{tabular}

Table 4: Numbers of Y12 mathematics students continuing to Year 13 (A2) by student AS attainment and gender at Queensbury Park

\section{Focus Group}

The focus group data from QP came from discussions with students (anonymised below) in the summer term of Year 12 (2008), following the AS examinations, when students had decided whether or not they planned to continue. It is clear from our data that decisions taken at this point are not final decisions. Some students who aspire to continue do not yet know that their failure to pass AS will force them to rethink their plans. Of the eight students involved in the focus group discussions, two of them eventually returned to study mathematics in Year 13. Two of the three high attaining girls that stopped at the end of Year 12 were part of the group.

\footnotetext{
${ }^{1}$ The Advanced Level Information System (ALIS) provided value added grade predictions based upon students prior attainment (http://www.cemcentre.org/RenderPage.asp?LinkID=11610000)

2 The only other two historians were also studying physics, strongly associated with continuing to A2
} 
When studying student decision-making in a school case such as this we considered internal school factors as well as the external factors that will have an influence. The latter category is where we are more likely to be able to generalise. We proceed by reporting the case study discussions in two sections. We recognise that the choice and organisation of data is theoretically informed and can only present a partial view - our overarching aims here are to explore a) the students' reasons for taking mathematics in the first place and b) the reasons for student withdrawal from A level mathematics. Although (a) is not the principal focus for the paper we do not think that (b) can be adequately understood apart from (a) as the departmental/school factors affecting choice are not independent from those influencing withdrawal.

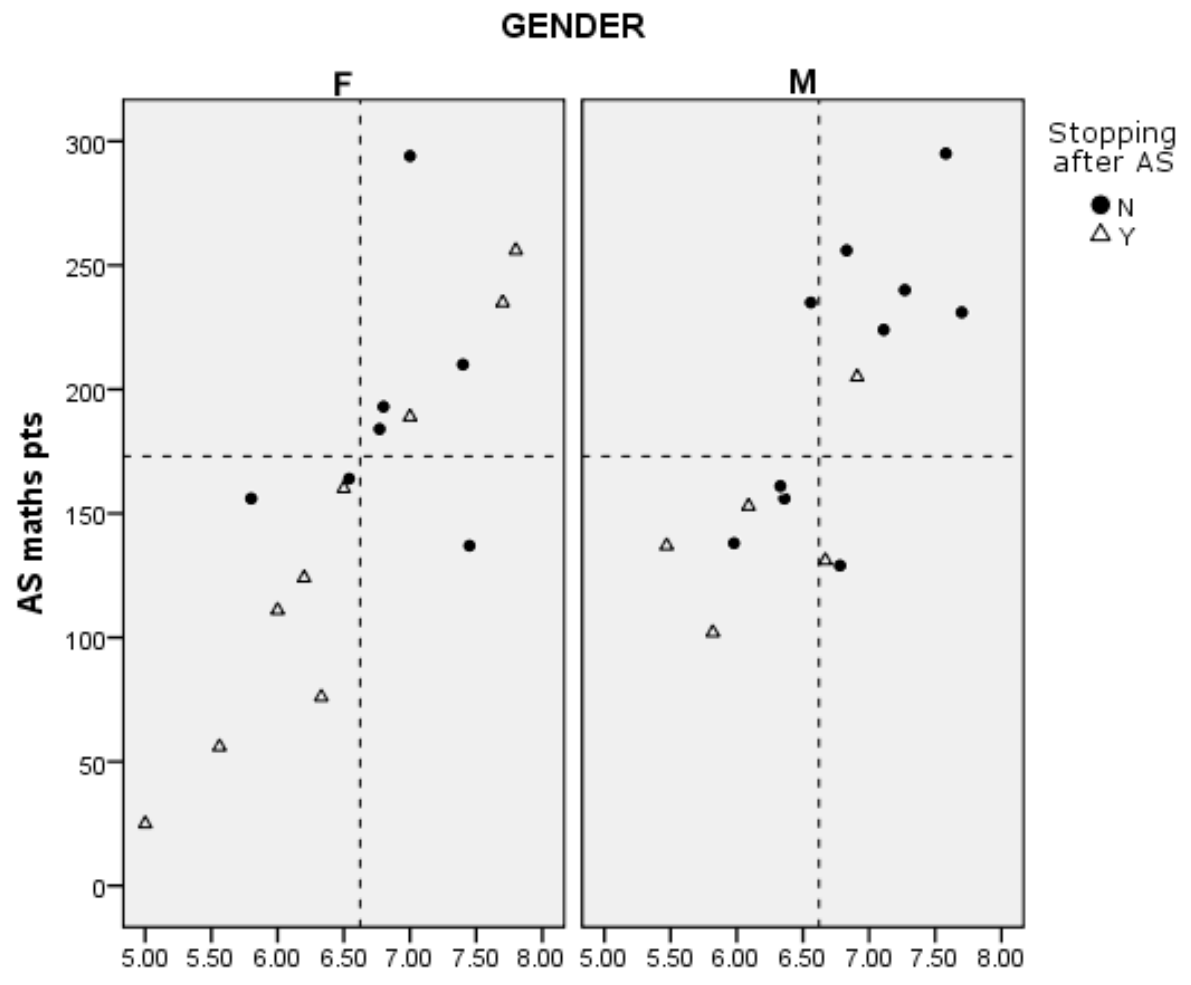

Average GCSE score

Chart 1: Male and female students stopping mathematics at the end of year 12, by average GCSE grade and points score from Year 12 mathematics (means for the cohort shown as dashed lines)

\section{Deciding upon A level Mathematics}

When selecting subjects for AS study there were two critical and interrelated factors that dominated decision-making; success at GCSE performance coupled with enjoyment of the subject, factors that have been acknowledged elsewhere (Brown et al., 2008).

I wanted to do what I enjoyed in year 11 and I was good at. (Kelly)

The feeling of enjoyment is, for many, closely related to experiencing success but enjoyment/success at GCSE does not always transfer well to the A level as we show below. Nonetheless, for many students enjoyment through success (being "good at") is a powerful motivator in the decision-making process.

Secondly, the students considered the combination of their proposed subjects and whether they complemented one another. Sometimes mathematics was at the heart of the choices made, whereas for other students it sat on the periphery:

I did three subjects that were linked. I did media, English and drama. (Charlotte)

Because of physics I chose maths as well. (Alice)

Although embarking upon further education for qualifications that will gain entry into higher education and/or employment, only one student indicated that subject choice had been related to specific career 
aspirations. This seems surprising given the data presented by Matthews and Pepper (2007) which suggests that the usefulness or exchange value of mathematics for future courses or careers is fairly influential in the choice process. Charlotte stated that she selected English because she wanted to be a primary school teacher. It is not surprising perhaps that Charlotte is considering dropping mathematics which does seem to be quite separate from her other interests. Georgia, in stark contrast to Charlotte, had several possible career aspirations so had considered a diverse combinations of subjects, all of which might possibly be helpful in the future. For her, mathematics fits with the other subjects. Krogh \& Thomsen (2005) argue, in the context of school physics, that 'border crossing' between the different subject cultures (classroom, discourse, study patterns, etc) can present substantial discontinuities for learners. In Charlotte's case we might expect that this has contributed to her sense of disconnection with mathematics which leads to her being in our focus group.

All students felt that they had made positive choices in their subject selection; not having to study a subject because of a dislike of the other alternatives on offer. Such decisions take into account a student's informal judgements about chances of success in different subjects. Faith, when considering history and the science subjects, decided to select history because she felt she was more likely to be successful in her final grade due to the history department's strong reputation.

Schools impact decisions to choose subjects not only through reputation of teachers/departments but through the organisation of the curriculum. The clustering of subjects into 'option blocks' is needed for administrative expediency on behalf of the school and can present a constraint if certain combinations of subjects are prevented, thus reducing students' 'freedom of choice', especially for those already considering future careers. Having said that, such clashes would tend to occur for students taking less common combinations of subjects:

I wanted to do German but my German clashed with music so then I was like going to change it to biology but then that clashed with music as well (laughs) so I had to change it to chemistry. (Georgia)

Such a constraint on subject selection led to Georgia studying chemistry as an AS level when it was, actually, her third choice after German and biology.

Drawing on the work of Bourdieu (Bourdieu, 1977, 1998; Bourdieu \& Passeron, 1977) and those who have applied his work we contend that choice is a problematic sociological construct (Ball, Davies, David, \& Reay, 2002). Although students (and policymakers) may believe that they alone are responsible for all decisions they will have been affected consciously and sub-consciously by, for example, parents, friends, teachers and the careers service as well as by the particular social milieu in which they have grown up. Bourdieu explained that "we can always say that the individual makes choices, as long as we do not forget that they do not chose the principle of their choices" (Bourdieu \& Wacquant, 1989, p. 45). One of the interesting factors for us is how parental attitudes towards the study of mathematics have shaped the students' dispositions towards the subject. Although the parents' role is often described as being only one of guidance, advice and reassurance it is much more influential, albeit this influence is often difficult to recognise. In some cases parents have limited knowledge of current educational practices but we expect that most have some personal sense of a hierarchy of subjects. Such matters are regularly reported in the media, for example elite universities' concerns about the proliferation of 'soft' qualifications. The students report that parents' input into the decision-making process is often quite general, for example 'do those you're best at' or 'do those you like'. Such advice can be based on the belief that these factors, hopefully, will ensure that the students will be inspired to study, resulting in examination success. However, whether we can take this at face value remains to be seen as the students' embodied dispositions (which make them more or less likely to select certain courses of study) have already been shaped by their home environment. So, whilst the student responses suggest that parents are not very interventionist in the decision-making process, there is clear evidence of how some parents are influencing students' decision-making quite strongly, although this is not always recognised. Interestingly, Charlotte is one example of explicit parental intervention.

I discussed it with my mum and dad and then I sort of got pressured into doing maths. Because I did English, media and drama, they're all linked, and then she [mother] just wanted me to...have something to fall back on. (Charlotte)

Although there is no suggestion of any conflict between the students and their parents at the time of decision-making, for Charlotte, at a later date when she begins to lose her confidence in her mathematics 
ability, she expresses some resentment towards her mother about this influence. In contrast, Tom's parental influence was more subtle. Tom claimed that he had been responsible for all decisions relating to subject selection though he had discussed his options with his parents.

But in the end it was my choice. (Tom)

However, he later unwittingly revealed how his father might have had more of an influence on him:

My dad's got a Masters in mathematics so I can just ask him about a lot of the stuff. (Tom)

It is not easy for the students to recognise or acknowledge the particular influence that parents have upon them but most of the students believed that, although consultation may have taken place, final subject choice was determined by them.

Similarly, older siblings who had already completed A level study and taken a particular subject at an earlier date influenced a few of the students. We have already mentioned how the reputation of teachers and departments can inform choices. Teachers might also seek to influence the way students perceive themselves and the options available, offering advice and encouragement.

I spoke to him [maths teacher] and he was like 'you should definitely be one at the top of the list to carry on doing maths'...Most teachers just said 'do my subject'. (Kelly)

As indicated above, Kelly and her fellow students were aware that, although teachers might offer encouragement, they were also concerned to recruit viable numbers so that courses would run. So although they enjoyed the affirmation of being encouraged to take the different subjects they were also a little sceptical about the motivations of some teachers. The students in the group were critical of the careers lessons that they had received in Year 11 believing them to be insufficient, unhelpful and of a quite general nature. Most decision-making was reportedly made largely in consultation with parents.

\section{Transitions into, and out of, Advanced mathematics}

The students found the transition from GCSE to AS level difficult in all of their subjects. This was not so much to do with curriculum continuity but rather a shift in the expectations and demands made upon them by teachers. The transition was marked by a pedagogic discontinuity. Once in Year 12 the students realised how much classroom activities had been teacher-led in Year 11.

It was so hard because everything is spoon-fed at GCSE. At the time you don't really realise it, until you're doing A level. (Kelly)

At GCSE it was like you basically knew what the question was going to be and you just had to remember the formula - there you go. That's it! (Faith)

Teachers had taught the students the processes enabling them to achieve examination success. However, in the sixth form there was a greater reliance on independent learning coupled with a greater and harder workload.

They say 'well it's really up to you how much work you do to be honest and that will determine your grade'. (Tom) If you don't learn it completely in lesson then you have to go home and do it yourself. (Amy)

People say it's going to be a lot harder but you don't really realise how much harder it's going to be. And like how much work that we had to actually do as well like there was so much stuff. (Alice)

The shift in teaching styles and working culture greatly affected the experiences of the learners of mathematics. In our interview with the head of department (replicated across the 16 schools) the view was expressed that success in A level mathematics demands a particular kind of work ethic. This is not described in the same way in all of the schools but does have the common elements of independence and hard work. Moreover, they believe that students who do not have this work ethic will not be successful. For many they believe that this requirement is different in mathematics than in other subjects. Although we do not explore this expectation further here suffice to say that this sense of distinction, of mathematics being different, helps to reinforce the aforementioned notion of boundary crossing, particularly for students with very mixed combinations of subjects. 
We note at this point that these students remained in the same 11-18 school for their GCSEs and then their A level studies and so did not have to deal with the additional challenge of reorienting themselves to a new school setting with new teachers, peers, building and cultures.

During Year 12 the students studied three modules: Core 1, Core 2 and Mechanics 1. The module that seems to have caused the most problems, for this focus group at least, was Mechanics. In particular, the girls (more likely to be non-physicists) in the cohort found this a very demanding module and there was resentment that mathematics teachers had not informed them about the inclusion of this module in the syllabus and of the nature of the module and its apparent similarity to physics.

After every mechanics lesson I had a headache. Without fail!...I did not know mechanics would be in maths...It's dreadful and everyone hates it. (Kelly)

It just wasn't even mentioned until we like got into the lessons. 'We're doing mechanics.' It's like 'we're doing what now?' I spoke to my form tutor and she was like 'yeah, I didn't like mechanics, it's just physics in disguise'. (Faith)

The girls in the focus group all agreed that the inclusion of mechanics in the mathematics course was an unpleasant surprise and that if they had known about it they would not have considered mathematics A level as one of their options. The dislike of mechanics, due to its perceived difficulty, became a principal reason for students not to proceed with mathematics to A2. What we cannot say is whether this was influenced by the students' relationships with the teachers of the various modules or the quality of the teaching. It would be unfair to pin the blame on mechanics, per se, but when combined with points made earlier about the relationship between subject mixing with physics and attainment at AS some interesting questions arise. Note that these points only apply to the focus group data; there are many students who have been successful and plan to continue to Year 13.

The group was worried that the work in Year 13 would be harder than that experienced already, and Year 12 had been much harder than they had imagined it would be:

Core 3 and 4 are supposed to be harder. I don't know if I can cope with that. (Amy)

This perception of difficulty, combined with a loss of the enjoyment that is associated with success led to a lack of confidence and, in the case of Charlotte, total antipathy toward mathematics.

I've struggled with AS level so there's no chance I'm going to do A2. Because I just think my brain won't cope with it, I just think it will leave me depressed. I've actually just gone from one year of really liking maths to now where I actually despise maths. I hate it so much, with a passion! (Charlotte)

Matthews and Pepper (2007) suggest that feeling able to cope was more important for girls than for boys when considering continuation with mathematical study. However, it is not easy to disentangle these issues of gender, self-efficacy, subject mixing and so on.

There was a concern amongst the group that a disproportionate amount of time was spent on their mathematical studies at the expense of other subjects. This might not have been the case across the full student group of Year 12 mathematicians but given that the focus group included higher and lower attaining students this sentiment probably reflects that of the wider group. This had led the students to re-evaluate the level of effort required to achieve their A level target grades in each of their subjects. They were prepared to sacrifice taking a fourth A level in order to ensure success in the remaining three.

I don't think I'll get really good grades in maths because of mechanics ... so if I get really low [grades] then there's not much point in carrying on with it even though I do like it. (Amy)

Students, as in the case of Amy above, were prepared to take subjects that they found less enjoyable in order to ensure examination success. Whereas enjoyment of a subject had been crucially important for its selection at AS level this is of lesser importance when considering continuation to Year 13. As well as enjoyment, students were also beginning to question the relevance of mathematics for their proposed career.

I don't see how it [mathematics A level] will have any real relevance on my career or the people around me. I can see that maths can be seen as a valuable qualification but I'm not sure what relevance it has in the wider scheme of things. (Tom) 
Here students are thinking strategically about the subjects taken to A2 level especially when considering university entrance requirements which rely on the grades achieved at examination. Thus, students need to be selecting subjects where they will minimize the risk of failing to meet their grade offers from universities.

I'm better at history definitely and I think I've got more of a chance of getting an 'A' in history so that's why I'm dropping maths. (Faith)

Faith achieved an 'A' grade in her AS mathematics but did not proceed to A2 in order that she could concentrate on her three other subjects in which she felt that she was capable of greater success, so that she could secure a place to Oxford University. Mathematics was not considered relevant to this application so she was prepared to accept an 'A' grade at AS level rather than a lower grade at A2 level. Students are, therefore, playing the system with varying degrees of sophistication in order to maximise their chances of gaining entry to the university of their choosing. Many of their decisions not to progress mathematics to the next level were supported by parents. The students perceive that the school was concerned about the potential number of students that might not proceed to A2.

It's been like a lot of the teachers have been panicking a bit, thinking that everyone's dropping it because of mechanics so it's more like the maths teachers trying to assure you that we won't be doing mechanics next year. (Kelly)

Naturally, schools have to manage the delicate balance between recruiting viable numbers of students so that classes run, whilst ensuring low failure rates. It is not just teachers that are subject to market economics and what Ball (2003) calls the 'terrors of performativity' as students are now all too aware of the hierarchy of universities and of the different opportunities that might arise from different higher education pathways.

\section{Summary}

The data reported here point to a number of important issues for the recruitment and retention of A level mathematics students. Our survey data from Year 12 students indicates that at the time of the surveys more students had withdrawn from their AS mathematics course than from any other subject. Although the percentage is higher from IT subjects this high figure for mathematics is striking. Whether or not this pattern would be repeated in colleges and sixth form centres is unclear but given that our data covers a variety of schools we can confidently say that there is a problem with AS drop out in mathematics. Some of the reasons for this are already outlined in the literature and are reinforced here, including perceived difficulty, lack of confidence, curriculum content and relative success.

We also note that the differences between schools in this particular year (2007-8) are striking with withdrawal rates varying from $0-21 \%$ of the starting group although admittedly some of the numbers are quite small. When we look at the proportions of the Year 12 group planning to continue to Year 13 the numbers are even more wide ranging (5 - 38\%) and although some of these groups are small enough for a few students to make a large difference the variation is no doubt real and sizeable.

From our interviews with heads of department it is clear that the particular policies of schools, including entry requirements and conditions for continuation, vary and that these would make some contribution to these variations. For example, schools allowing students to start AS with a GCSE mathematics C grade are more likely to have higher withdrawal rates. However, policies on paper and in practice are not always well aligned and so it would be difficult to account for these participation differences by policy alone. Indeed a more detailed statistical analysis would be required. We have not explored the data in sufficient depth herein to fully appreciate these differences as our aim in this paper is to sketch out the extent of the variation in a sample of schools. Analyses of completion data from the National Pupil Database (Author, 2009) suggest that a sizeable amount ( 20\%) of the unexplained variation in whether or not a GCE level student completes AS maths is attributable to the school or college attended, taking into account prior attainment at GCSE and a range of other factors.

We are not able to say whether reporting these variations in withdrawal the year 2007/8 will be similar to the following year (2008/9) and so are undertaking a further set of surveys to ascertain whether there is any stability about these between-school differences. In our case study school, Queensbury Park, of the thirtytwo survey respondents, fourteen either withdrew from AS or planned to not continue to A2, which is one of 
the higher figures in our sample of schools. The second part of this paper sought to explore some of the reasons behind the decisions to not continue to A2 and the extent to which they were influenced by individual, peer and school level factors.

The issue of subject mixing is an important one as it does seem that this affects not only the students' likelihood of meeting their predicted grade but thereby their success and feelings of self-confidence. Moreover, some of them are thinking quite strategically about the grades they require in order to secure their preferred university place. Where mathematics is not a specific requirement, other A levels offer less risky routes to making the grade. For those students for whom mathematics complements their other courses of study, particularly physics, the place of the mechanics module in Year 12 had not proved a great disincentive. This is in contrast to the non-physics students who single out this aspect of the course for particular criticism. What we cannot say here is that this is due to mechanics per se as this is no doubt tangled up with the teaching and learning of this module, the relationship with this and other teachers and so on. That said, the school has moved this module to the Year 13 curriculum for the following year so recognise the detrimental effect that it has had upon engagement, attainment and future participation.

Many of these issues arise in the other case study schools and so it is unclear what might be unusual about Queensbury Park in this particular year. Important staff changes happened in the department during the year but this did not have a direct impact upon the AS mathematics. There do appear to be two gender related issues here that are worthy of note, although we would not want to make generalisations from such a small sample. Firstly, girls not continuing to A2 come from the full range of GCSE attainment whereas for the boys they tend to be lower attainers, although the driving factor here is most likely to be subject mixing. Secondly, a few of the girls with lower GCSE prior attainment have done particularly badly in the transition to A level. Again this is partly to do with subject mixing and the 'border crossing' which results.

What we have tried to do here is explore issues of withdrawal from AS mathematics and non-continuation to A2 using mixed quantitative and qualitative data to identify issues for further exploration and to highlight the challenges of trying to understand these phenomena more fully. It is clear to us that the actions of students are framed by the social context in which they are learning and growing up. So, whilst gender and subject choice have an impact on likely continuation with mathematics, so does the curriculum shape and experience in the classroom. Moreover, parents and peers are also influential, albeit in rather hidden, subtle ways. If the ambitious targets for the completion of A level mathematics are going to be met then we need to better understand the ways in which student and school level factors combine. This paper contributes to that understanding.

\section{Acknowledgements}

We are grateful for the support given by the ESRC (RES-061-25-0035) which has made this research possible

\section{References}

Author (2009a)

Author (2009b)

Ball, S. (2003). The teacher's soul and the terrors of performativity. Journal of Education Policy, 18(2), 215228.

Ball, S., Davies, J., David, M., \& Reay, D. (2002). 'Classification' and 'Judgement': social class and the 'cognitive structures' of Higher Education. British Journal of Sociology of Education, 23(1), 51-72.

Bourdieu, P. (1977). Outline of a Theory of Practice. Cambridge: Cambridge University Press.

Bourdieu, P. (1998). Practical Reason. Cambridge: Polity Press.

Bourdieu, P., \& Passeron, C. (1977). Reproduction in Education, Society and Culture. London: Sage Publications Ltd.

Bourdieu, P., \& Wacquant, L. (1989). Toward a reflexive sociology: a workshop with Pierre Bourdieu. Sociological Theory, 7(1), 26-63.

Brown, M., Brown, P., \& Bibby, T. (2008). "I would rather die": reasons given by 16-year-olds for not continuing their study of mathematics. Research in Mathematics Education, 10(1), 3-18. 
Committee on Science, Engineering and Public Policy. (2007). Rising above the gathering storm: energizing and employing America for a brighter future. Washington, DC: The National Academies Press.

Gago, J. M. (2004). Increasing human resources for science and technology in Europe. Brussels: European Commission.

Hernandez-Martinez, P., Black, L., Williams, J., Davis, P., Pampaka, M., \& Wake, G. (2008). Mathematics students' aspirations for higher education: class, ethnicity, gender and interpretive repertoire styles. Research Papers in Education, 23(2), 153-165.

Krogh, L., \& Thomsen, P. (2005). Studying students' attitudes towards science from a cultural perspective but with a quantitative methodology: border crossing into the physics classroom. International Journal of Science Education, 27(3), 281-302.

Matthews, A., \& Pepper, D. (2007). Evaluation of Participation in A level Mathematics: final report. London: Qualifications and Curriculum Authority.

Mendick, H. (2005). Mathematical stories: why do more boys than girls choose to study mathematics at ASlevel in England? British Journal of Sociology of Education, 26(2), 235-251.

Mendick, H. (2008). Subtracting difference: troubling transitions from GCSE to AS-level mathematics. British Educational Research Journal, 34(6), 711-732.

Roberts, G. (2002). SET for success: The supply of people with science, technology, engineering and mathematics skills. London: Department for Education and Science.

Rocard, M. (2007). Science Education Now: a renewed pedagogy for the future of Europe. Brussels: European Commission.

Smith, A. (2004). Making Mathematics Count. London: The Stationery Office. 